\title{
Influence of Evacuation Walkway Design Parameters on Passenger Evacuation Time along Elevated Rail Transit Lines Using a Multi-Agent Simulation
}

\author{
Zihua Pan ${ }^{1,2, *(\mathbb{D})}$, Qingchao Wei ${ }^{1}$, Olav Torp ${ }^{2}$ and Albert Lau ${ }^{2}$ (D) \\ 1 School of Civil Engineering, Beijing Jiaotong University, Beijing 100044, China; qcwei@bjtu.edu.cn \\ 2 Department of Civil and Environmental Engineering, Norwegian University of Science and Technology, \\ 7491 Trondheim, Norway; olav.torp@ntnu.no (O.T.); albert.lau@ntnu.no (A.L.) \\ * Correspondence: panzihua@bjtu.edu.cn; Tel.: +86-152-0134-3069
}

Received: 30 September 2019; Accepted: 29 October 2019; Published: 31 October 2019

check for updates

\begin{abstract}
Passenger evacuation on elevated railway lines has always been an important issue for elevated rail transit safety management, because it is challenging to evacuate passengers efficiently in the event of man-made calamities and natural disasters. Therefore, an evacuation walkway has been designed as a primary solution to assist passenger evacuation during an emergency on elevated rail transit lines. However, investigations on how evacuation walkway designs influence passenger evacuation time are still limited. This study established two evacuation scenarios of interval evacuation on elevated rail transit lines and put forward a new evacuation time measurement method, based on the concept of 'evacuation time for passengers leaving the evacuation walkway risk zone'. Then, the evacuation time for 90 combinations of entrance widths and walkway widths was simulated by a multi-agent evacuation simulator, Pathfinder, considering 1032 passengers being evacuated both unidirectionally and bidirectionally. The results show that the entrance width and walkway width have a combined effect on passenger evacuation time. An increase in the walkway width from $0.7 \mathrm{~m}$ to $1.5 \mathrm{~m}$ may potentially reduce the evacuation time by $54.5 \%$ in unidirectional evacuation, and $35.2 \%$ in bidirectional evacuation. An increase in the entrance width results in a noticeable evacuation time fluctuation when the walkway width is 0.7 and $0.8 \mathrm{~m}$ for both evacuation scenarios, while in a bidirectional evacuation, a noticeable fluctuation also can be observed when the walkway width is within the range of 1.4-1.5 m. According to the study, a potentially good design parameter combination for a newly built evacuation walkway is $1.3 \mathrm{~m}$ and $1.4 \mathrm{~m}$ for the walkway width and entrance width, respectively. The findings from this study may provide a useful reference in the optimization of the design of evacuation facilities and improvement of passenger evacuation safety in rail transit systems.
\end{abstract}

Keywords: passenger safety; Maglev transit; evacuation time; multi-agent simulation; evacuation walkway; parametric design

\section{Introduction}

Due to the increase in man-made accidents and natural disasters, passenger evacuation in a rail transit system has became a more prominent research issue for emergency response planners, transport engineers and policymakers [1-6]. It is challenging to evacuate a mass volume of passengers in a well-organised and highly-efficient way in a rail transit system because of the uncertainty of accidents and complex nature of individual characteristics [7-9]. Passenger evacuation in rail transit systems can be hard to predict, because the types and locations of accidents that occur in rail transit are unpredictable [10]. In many cases, passengers are required to evacuate quickly in a difficult-walking 
environment, e.g., through a tunnel with low visibility or a viaduct with limited walking space [11,12]. The tendency for passengers to be caught in danger, e.g., falling over or panicking in a congested and unfamiliar place, is high. Furthermore, distance to safety is an uncertain factor for passengers. While the priority is to evacuate passengers to the nearest station in case of an emergency, it remains a possibility that a train will be forced to stop at interval sections due to a train fire, train collision, power failure, etc. $[13,14]$. In this case, people might need to walk for a long distance to get away from the dangerous accident site before they reach the safety exits. Therefore, it is essential to provide a user-friendly and highly-efficient evacuation facility for passengers' safety in rail transit systems [15].

The evacuation walkway for Elevated Electromagnetic Suspension (EMS) Maglev transit may be one typical evacuation facility for rail transit systems. The EMS maglev track structure is known for having less space for evacuation in comparison to a conventional ballast or ballastless rail track structure (see Figure 1). The solution to that is therefore an extra elevated evacuation walkway, next to the rail transit systems. It is worth noting that an elevated walkway that is high from the ground might pose a problematic evacuation condition for passengers who are acrophobic [16].

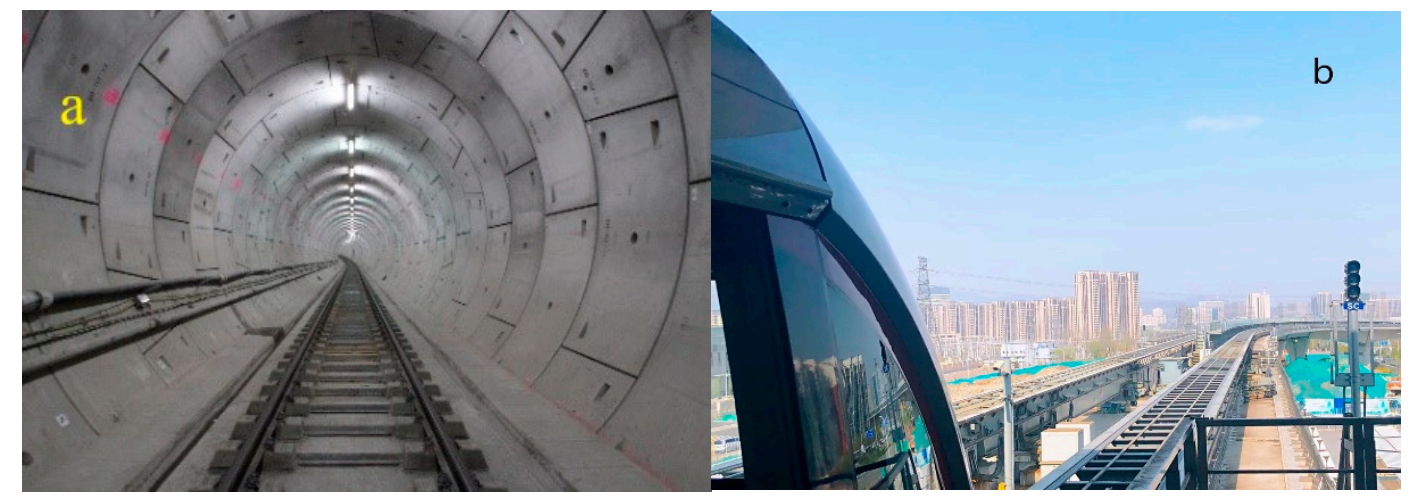

Figure 1. A track structure comparison of a metro system and an Elevated Electromagnetic Suspension (EMS) Maglev system: (a) a typical rail-track structure of a traditional metro system [17]; (b) EMS Maglev track structure of the Beijing Maglev Express.

Some research has shown that an appropriately designed evacuation walkway could improve the evacuation conditions in rail transit constructions. For instance, Habicht et al. [18] proposed a definition, together with a method, to calculate the effective width reductions under various conditions, based on pedestrian distribution observations in a pedestrian tunnel. They found that the actual effective width of the passageway is generally wider than that assumed in some design practices. Lundstrom et al. [19] discussed the relationship between a raised walkway width and people's evacuation behaviour in rail tunnels using a model of a tunnel walkway. They found that a walkway width of around $1 \mathrm{~m}$ leads to a higher moving speed, and there is a linear relationship between the dynamic flow of the crowd and the walkway width. Moreover, the evacuation walkway width consideration is a mandatory aspect of evacuation regulations in many countries. For example, the minimum walkway width in a tunnel of $<20 \mathrm{~km}$ should be at least $0.75 \mathrm{~m}$, while that for tunnels $>20 \mathrm{~km}$ should be at least $1.1 \mathrm{~m}$ according to EU regulations [20]. According to the design code of the Metro of China and the design code for Medium and Low-Speed Maglev Transit in China, the minimum evacuation walkway width should be $0.7 \mathrm{~m}$, which is the same as the recently built Copenhagen Metro [21-23].

The research mentioned above is useful for designing the evacuation walkway width, while the connecting parts between the train and the evacuation walkway may result in a bottleneck effect during the evacuation process [23]. For example, Fridolf et al. [24] found that train exit flows and walkway flows are likely to be constrained due to merging conditions in the evacuation process, and that merging increases the required time for evacuees to reach a safe place. Arturo Cuesta et al. [25] also confirmed the negative effect of the occurrence of merging on evacuation time through a field 
experiment in a mock rail car, with a single exit towards a lateral corridor. According to their data, the rail car exit flow and the walkway flow decreases when merging occurs.

According to the above-mentioned studies, it may be the case that the walkway width, along with the entrance width, of an evacuation walkway may together affect the passenger evacutation process; however, to date, only limited research can be found that discusses this combined effect on evacuation time in urban rail systems. As an example, the entrance width of an evacuation walkway is usually set as a constant or two to three different values, and the evacuation direction is not a consideration [24,25]. For countries like China, the minimum entrance width of evacuation walkway is $600 \mathrm{~mm}$, and for Japan the minimum entrance width of evacuation walkway is $660 \mathrm{~mm}$ or $800 \mathrm{~mm}$ for passengers with a wheelchair $[21,26]$

Therefore, the objective of this study is to find the combined effect of the entrance width and walkway width of an evacuation walkway on evacuation time and then to put forward a suggestion as to a potentially better design combination, which may result in a shorter evacuation time. The study flow and its corresponding contribution are as follows:

(i) Establish passenger evacuation scenarios in elevated rail transit lines and conduct a field survey on elevated Electromagnetic Suspension (EMS) transit lines in China. This aids in the collection of necessary information on passengers for the simulations in the second step.

(ii) Use a multi-agent simulator, Pathfinder, to calculate the evacuation time for 90 combinations of entrance widths and the walkway widths of an evacuation walkway. This aids in the study of the effect of the design combinations parametrically.

(iii) Analyse the combined effect of the two design parameters on evacuation time using a new evacuation time measurement. This aids in suggesting potentially good combinations of entrance widths and walkway widths for the design of an evacuation walkway.

\section{Methodology}

The methodology of this study consists of 2 parts. First, typical evacuation scenarios were surveyed, then passenger evacuation time was simulated by a multi-agent evacuating simulator, Pathfinder. The research process of this study is shown in Figure 2. Step (iii) of the study flow, mentioned in the introduction, is addressed in the results and the discussion.

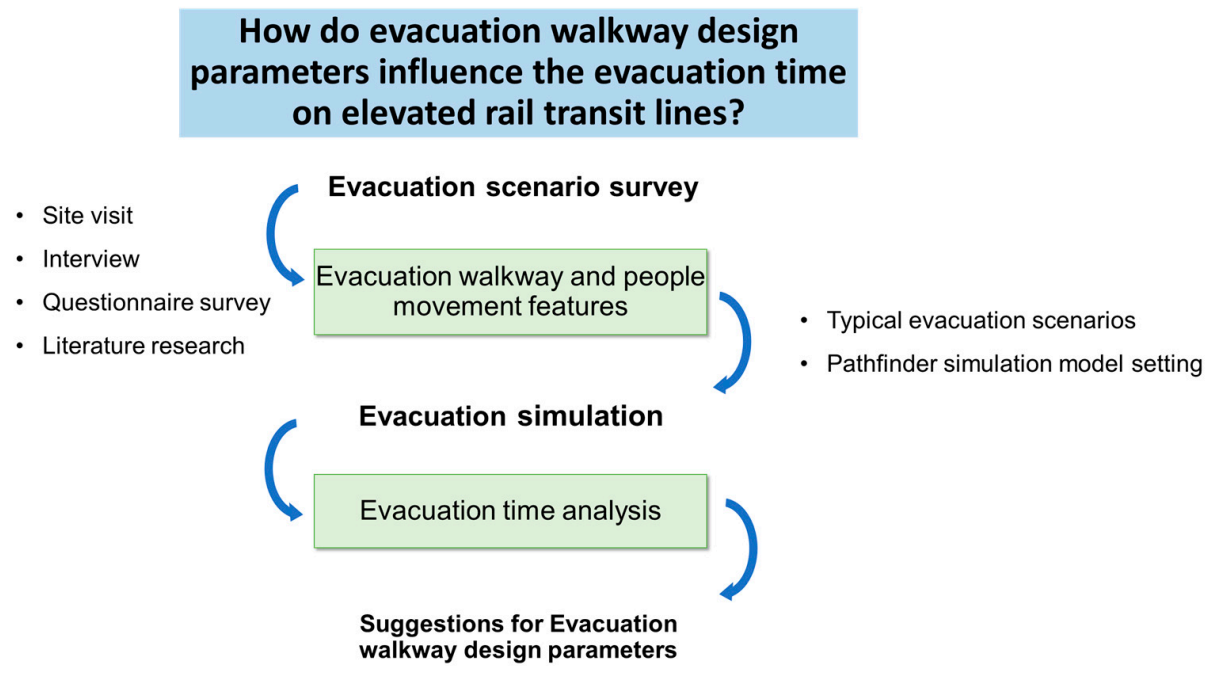

Figure 2. Research process.

\subsection{Evacuation Scenario Survey}

The purpose of the evacuation scenario survey was to obtain basic information to support the building of an evacuation simulation model, e.g., typical evacuation routes selected by the passengers and different evacuation walkway design features. 
The survey is divided into three steps: First, an interview of Maglev transit operators and construction companies in Changsha and Beijing, respectively. Information on, for example, emergency types, frequency of emergencies, and passenger evacuation patterns, is discussed and collected. Second, the design of the evacuation walkway is surveyed by visiting the actual evacuation routes on the Maglev transit lines in Shanghai, Changsha and Beijing. Finally, a questionnaire survey was conducted to obtain the basic features of passengers using Maglev transit, e.g., age, gender, level of education and simple self-estimated choice of evacuation routes. A total of 400 questionnaires were distributed at 5 Maglev transit stations in Changsha and Shanghai, and 338 valid ones were retrieved.

From the evacuation scenario survey, the following features of an interval evacuation on an elevated Maglev transit line are considered in the numerical evacuation simulation model.

A train is forced to stop at an elevated interval. The passengers must alight from the carriages, enter the evacuation walkway and evacuate along the walkway, until they reach the safety exits at the stations. The evacuation starts from the middle point of the interval, which is at the longest walking distance from both of the two nearest stations. Two scenarios are considered in the simulation, a unidirectional and bidirectional scenario, in which the passengers can evacuate with only one safety exit (the left one) or two safety exits, respectively. It is assumed that no working staff organized and coordinated the evacuation. The evacuation scenario is shown in Figure 3.

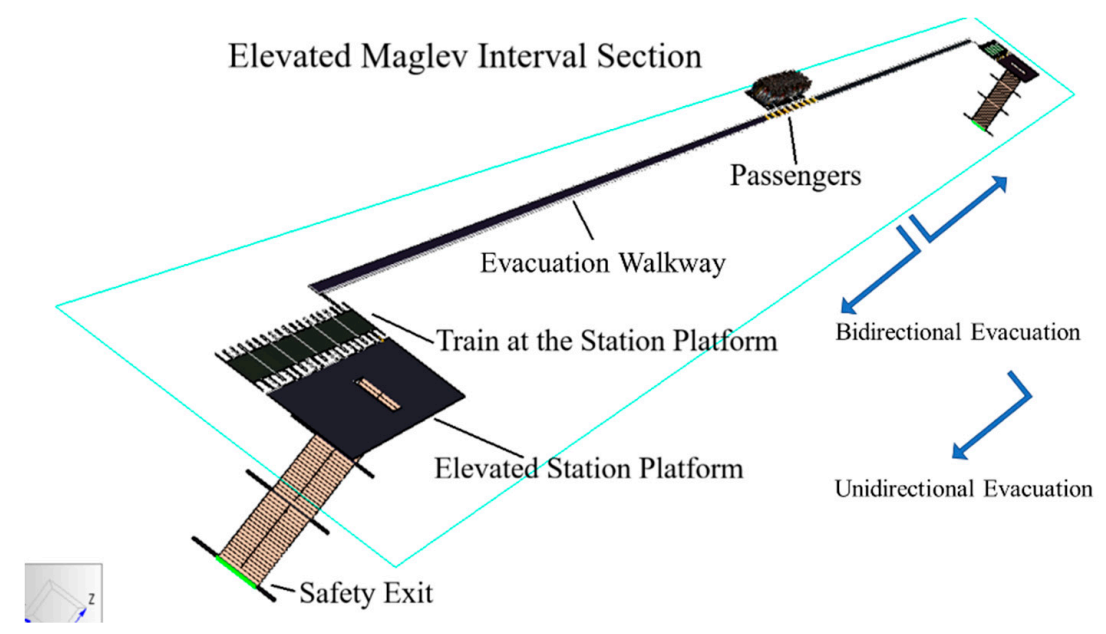

Figure 3. Schematic drawing of an interval evacuation scenario(s) on an elevated Maglev transit line.

\subsection{Multi-Agent Evacuation Simulation}

\subsubsection{Model Basis}

In this study, an agent-based evacuation simulator, Pathfinder, was used to simulate the process of passenger evacuation on an elevated rail transit line. It is known to be able to simulate the evacuation time for a mass passenger volume without having to set up a risky and expensive field experiment, e.g., construct an actual evacuation walkway with different designs and avoid safety risks in a crowded situation.

The steering mode of Pathfinder was chosen to simulate passenger movement. The steering mode is an agent-based model which is following Reynold's steering behaviour model [27] and refined by Amor et al. [28]. The passengers were set as an autonomous agent with different characteristics such as age, moving speed and pre-movement time [29]. In the steering mode, Pathfinder uses a combination of steering and collision handling mechanisms to control how the passengers achieve their goal in an emergency situation. These mechanisms allow the passengers to move along their path, deviate from the obstructions (interact with the environment and the other passengers) and still head in the correct direction toward their goal, the safety exits [30]. The algorithms and decision-making process when passengers follow the steering mode have been summarised in Figure 4, and the calculation process can be found in the technical reference of Pathfinder [31]. 

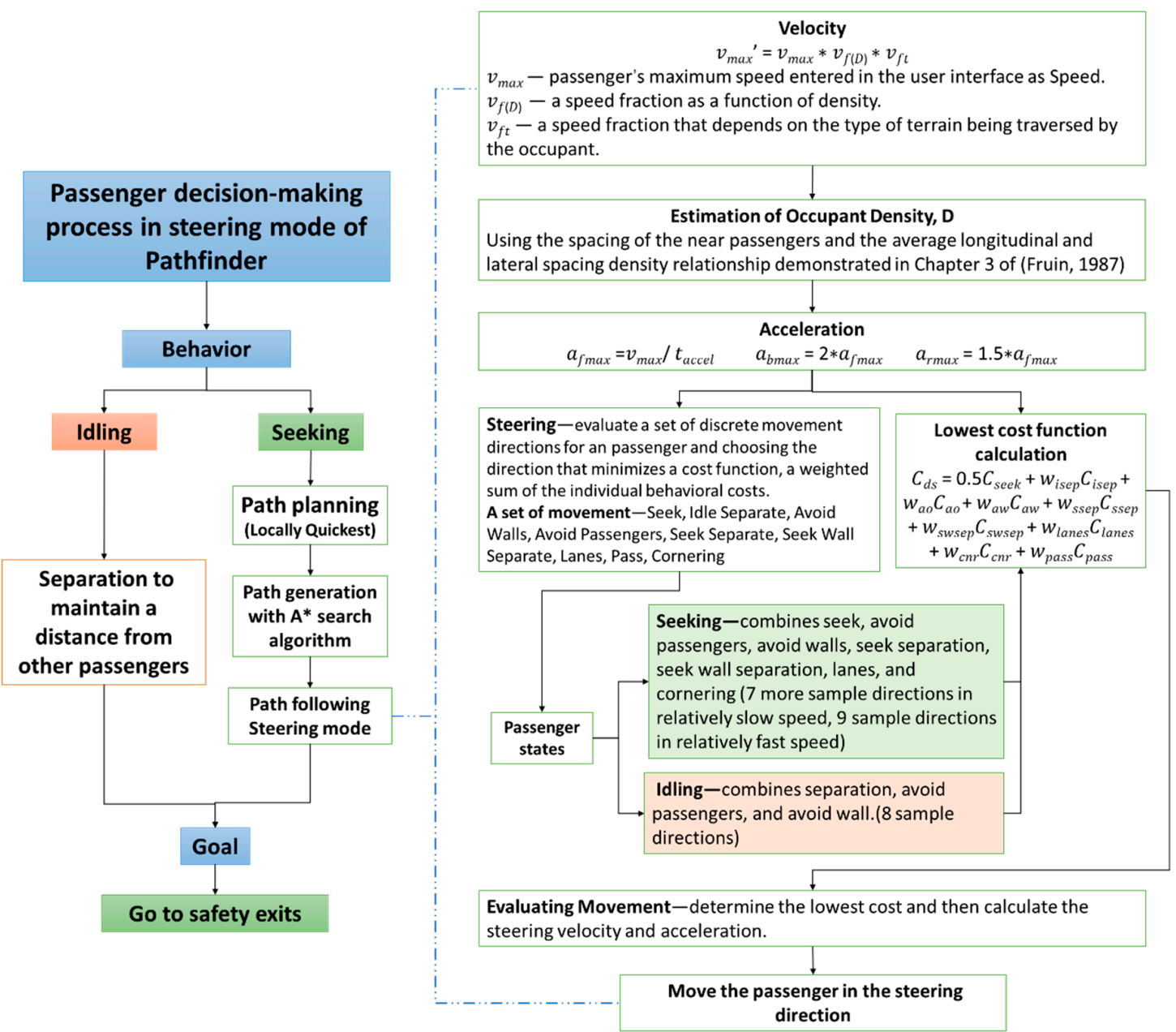

Figure 4. The decision-making process, when passengers evacuate following the steering mode in Pathfinder.

In Pathfinder, the construction environment of the elevated rail transit lines can be represented with a 3D geometry mode, i.e., evacuation walkway, station platform and stairs at different layers [31]. A navigation mesh is defined as a continuous 2D triangulated surface within a 3D geomtry model (see Figure 5). Passengers' motion takes place on this navigation mesh. The obstruction of seats in the train is implicitly represented as gaps in the navigation mesh. Since the passengers can only travel on the navigation mesh, this technique prevents the overhead of any solid object representation from affecting the simulation.

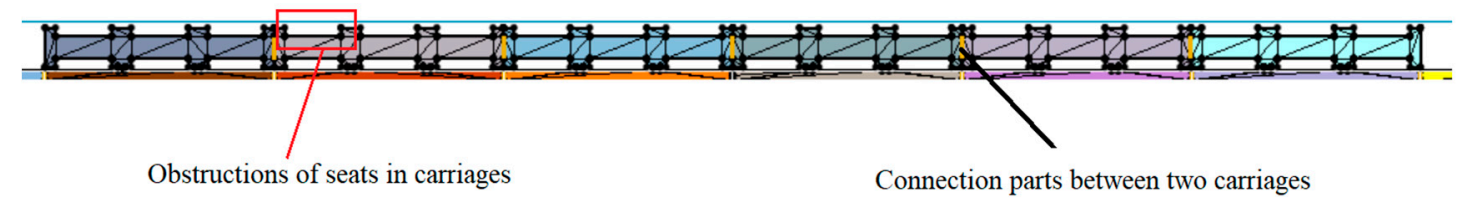

Figure 5. Navigation mesh of the EMS Maglev train in Pathfinder.

It is worth mentioning that the verification and validation of Pathfinder have been conducted before, e.g., by fundamental diagram tests, both in unidirectional and bidirectional flow and pedestrian behaviour tests at a corridor and stairway intersection [32]. The tests also showed that Pathfinder could provide a good representation of people's actual movement with respect to a real situation, and it has therefore been widely used in people evacuation research in recent years [33,34]. 


\subsubsection{Evacuation Time Measurement}

During an interval evacuation, passengers have to transfer from the train carriages to the evacuation walkway as quickly as possible and walk for a long distance, until they reach the safety exits at the stations. The passengers have different safety risks according to their various positions on the evacuation walkway. For example, in the case of a fire breakout in a Maglev train, passengers are at a higher risk if they are closer to the train carriages compared to the passengers who have already evacuated to the risk zone and those who are already outside of the risk zone [35,36]. Jumping fire and toxic gases have a higher tendency to harm those who are closer to the train compared to those who are further away from the train [37]. In addition, passengers are often more at risk of stampede when they are in the congested connection part between the Maglev train and the evacuation walkway. Hence, it is crucial to shorten the evacuation time for passengers, especially in leaving the train and the evacuation walkway risk zone during the evacuation. Measuring the evacuation time of different stages in an evacuation process might be helpful for improving the evacuation walkway design. Therefore, based on the evacuation scenario survey, a new measurement of evacuation time is proposed, which is as follows:

- $\quad t_{1}$-evacuation time, until all passengers have alighted from the train carriages.

- $\quad t_{2}$ - evacuation time, until all passengers have exited the evacuation walkway risk zone. The total length of the risk zone is the sum of the total length of the train and the fire separation length on both sides of the train $-16.5+89+16.5=132 \mathrm{~m}$. The fire separation length is $16.5 \mathrm{~m}$, which is $>12 \mathrm{~m}$, as required by the Fire Prevention Standard for Building Design of China [38].

- $\quad t_{3}$-total evacuation time start, until all passengers have passed through the safety exits.

The evacuation space division and definitions of $t_{1}, t_{2}$ and $t_{3}$ are illustrated in Figure 6 .
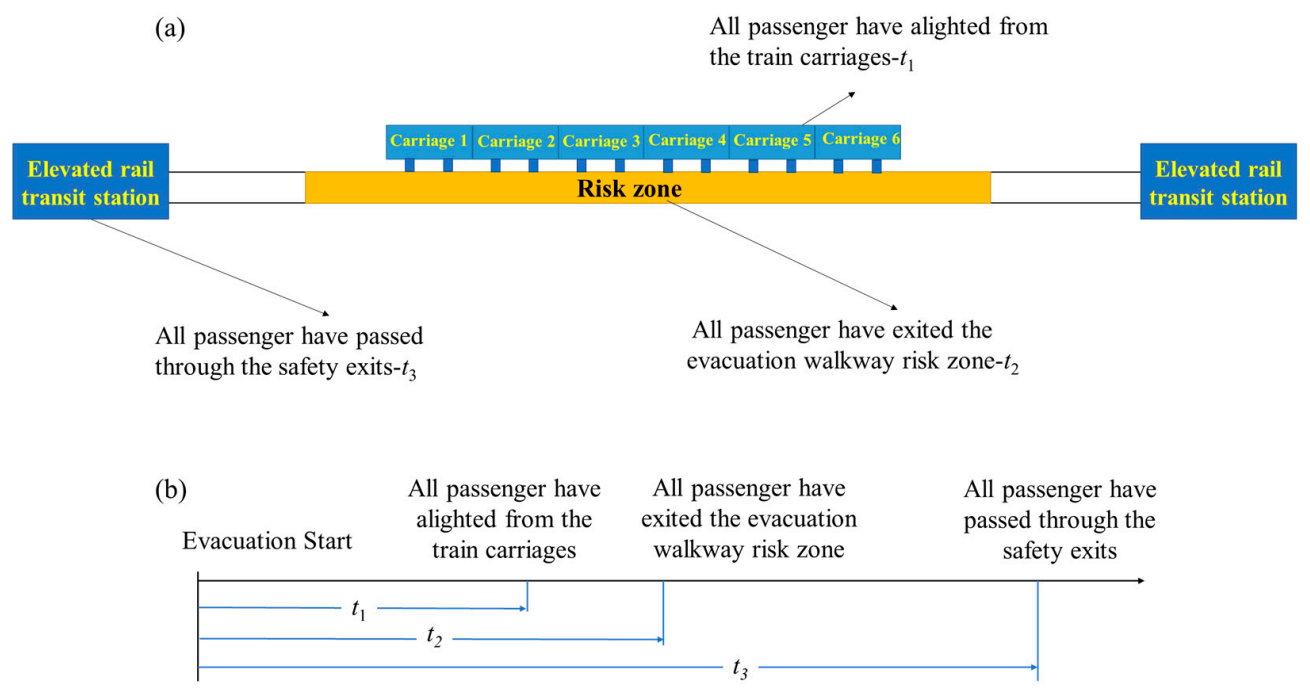

Figure 6. Concept of the new evacuation time measurement. (a) Evacuation space division of an interval evacuation and (b) the definitions of $t_{1}, t_{2}$ and $t_{3}$ evacuation times.

\subsubsection{Simulation Setting}

The parameters for the evacuation environment in the simulation model are listed in Table 1. They were formulated according to the information obtained from the evacuation scenario survey, as mentioned in Section 2.1. The first design parameter of evacuation walkway in the model is the entrance width, $d_{1}$. According to the evacuation scenario survey, the layout of guardrails determines the entrance width, $d_{1}$. For example, in the Beijing and Changsha Maglev lines, the guard rail spacing is $0.5 \mathrm{~m}$, which is a typical value in engineering practice to date. Even though the train door width is $1.4 \mathrm{~m}$ wide, the actual entrance width of the evacuation walkway remained $0.5 \mathrm{~m}$ (provided that the 
train driver aligned the train door with the entrance) because of a restriction imposed by the guard rail spacing. A lower bound of $0.5 \mathrm{~m}$ was therefore selected for the entrance width, $d_{1}$. Meanwhile, $1.4 \mathrm{~m}$ was selected for the upper bound in order to create room for the improvement of the actual width of a train door, if necessary.

Another design parameter is the evacuation walkway width, $d_{2}$. Considering the design specifications and the actual design conditions, the chosen range for $d_{2}$ in this paper was from $0.7 \mathrm{~m}$ to $1.5 \mathrm{~m}$, with $1.1 \mathrm{~m}$ as a median value [22]. Considering a $0.1 \mathrm{~m}$ interval for both variables, $90(9 \times 10)$ combinations of $d_{1}$ and $d_{2}$ were simulated.

Table 1. Parameters in the simulation model.

\begin{tabular}{ccc}
\hline Item & \multicolumn{2}{c}{ Content } \\
\hline Line type & Elevated EMS Maglev transit \\
\hline Marshalling & \multicolumn{2}{c}{ Six carriages } \\
\hline Length of each carriage & \multicolumn{2}{c}{$16.5 \mathrm{~m}$} \\
\hline Door number of each carriage & \multicolumn{2}{c}{ Two } \\
\hline Train door width & \multicolumn{2}{c}{ Parallel with the accident train } \\
\hline Location of evacuation walkway & \multicolumn{2}{c}{ Aligned with carriage doors } \\
\hline Location of the evacuation walkway \\
entrances
\end{tabular}

In addition to the parameters in Table 1, the passenger profile, such as the number of passengers, age group, shoulder width and moving speed, was considered in the model (see Table 2). The number of passengers was set to 1032, based on the current maximum passenger capacity for both Beijing Maglev transit and Maglev transit in China. The passengers' age group consideration from the questionnaires is summarized in Table 2. The age group was then utilized to estimate the moving speed and corresponding shoulder width, as suggested in the literature [39]. In the literature [40], it is stated that the moving speed of a passenger in a crowdy situation can be different at different locations, e.g., the passenger moving speed on a staircase and a slope is around $0.7-0.8$ times slower in comparison to that on a flat and straight section. Thus, a modification factor of 0.75 was considered for the staircases and connections between the train and the evacuation walkway in the simulation. The pre-action time, the time difference between a person noticing the accident and acting, was also considered in the evacuation time simulation. According to the Society of Fire Protection Engineers (SFPE) handbook of Fire Protecion Engineering, it is suggested that the estimated pre-action time until the evacuation 
start should be $<120 \mathrm{~s}$ for passengers who are awake but unfamiliar with the evacuation environment, the alarm system and the evacuation procedure [41]. In this study, to account for realistic passenger pre-action time behavior, it was assumed that the pre-action time followed a uniform distribution from $30 \mathrm{~s}$ to $120 \mathrm{~s}$.

Table 2. Passenger profile.

\begin{tabular}{ccccc}
\hline Group & Age & Percentage & Shoulder Width & Moving Speed \\
\hline Children & $\leq 15$ & $9 \%$ & $0.4 \mathrm{~m}$ & $0.78 \mathrm{~m} / \mathrm{s}$ \\
Young person & $16-35$ & $65 \%$ & $0.46 \mathrm{~m}$ & $1.22 \mathrm{~m} / \mathrm{s}$ \\
Middle-aged person & $36-55$ & $23 \%$ & $0.46 \mathrm{~m}$ & $1.17 \mathrm{~m} / \mathrm{s}$ \\
Elderly people & $\geq 56$ & $3 \%$ & $0.46 \mathrm{~m}$ & $0.75 \mathrm{~m} / \mathrm{s}$ \\
Total number of passengers & \multicolumn{3}{c}{0.75} \\
Moving speed modification factor & Uniform distribution on $[30 \mathrm{~s}, 120 \mathrm{~s}]$ \\
Pre-action time & Steering \\
The moving mode in Pathfinder &
\end{tabular}

\section{Results}

\subsection{Number of Iterations for the Simulation}

Because of the random effect in the passenger profile in the simulation model, the average evacuation time was used to represent a evacuation condition that is closer to reality. Therefore, the proper iteration times for each combination of the entrance width, $d_{1}$, and walkway width, $d_{2}$, should be considered. To do that, three combinations of $d_{1}$ and $d_{2}$ in bidirectional evacuation were selected, e.g., the minimum, intermediate and maximum combinations of $d_{1}$ and $d_{2}$. Each combination was iterated 50 times. The randomization function in Pathfinder randomized every iteration. The mean value of the total evacuation time $t_{3}$ of a different number of iterations, $K$, were compared, and the difference in the percentage of the mean evacuation time, $t_{3}$, is listed in Table 3 . It was observed that changing the number of iterations from 5 to $50 \mathrm{did}$ not result in a remarkable difference. Therefore, 5 iterations was selected for each simulation combination, and the averages of $t_{1}, t_{2}$ and $t_{3}$ were used for analysis.

Table 3. $t_{3}$ of a different iteration number for three combinations.

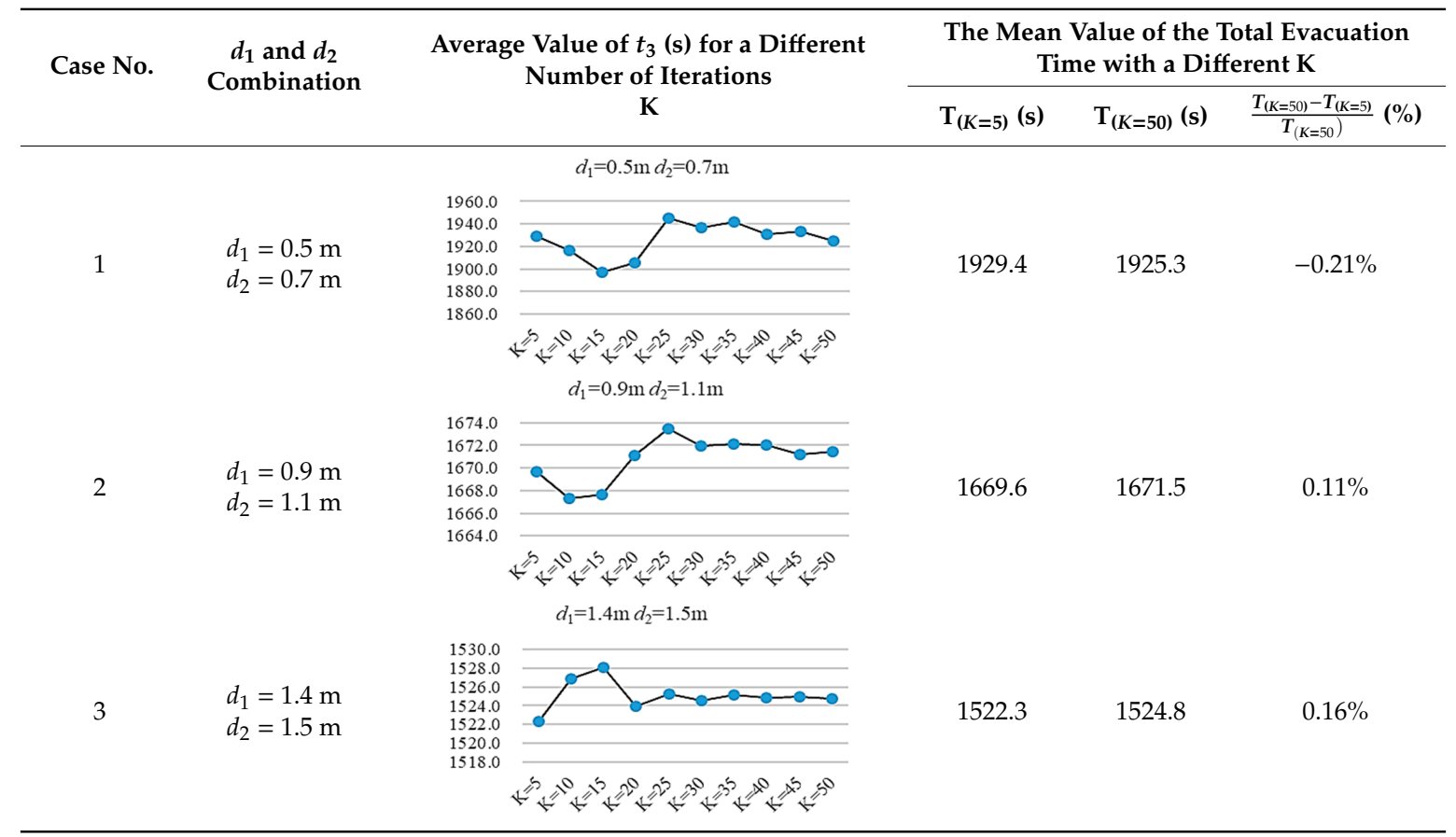




\subsection{Bidirectional vs. Unidirectional}

The maximum and minimum values of $t_{1}, t_{2}$ and $t_{3}$ of 90 combinations for bidirectional and unidirectional evacuation are illustrated in Figure 7. It can be seen that unidirectional evacuation took longer than bidirectional evacuation. This is to be expected, because in unidirectional evacuation, the passengers had only one possible exit. Additionally, altering the combinations of the evacuation walkway design parameters, $d_{1}$ and $d_{2}$ resulted in a broader difference between the maximum value and minimum value of $t_{1}, t_{2}$ and $t_{3}$ in unidirectional evacuation, compared with bidirectional evacuation.

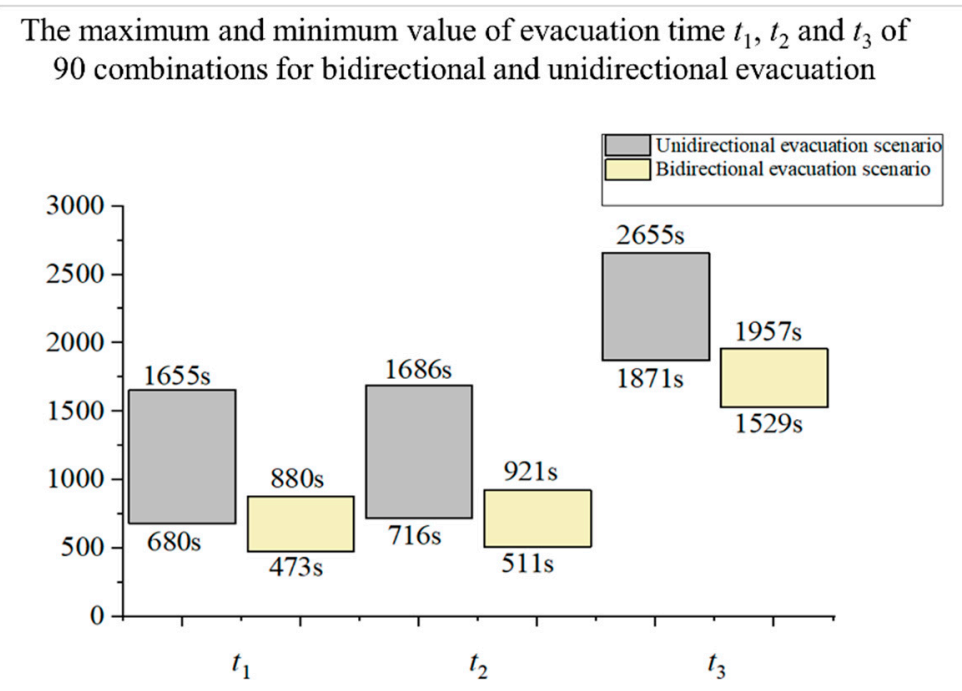

Figure 7. The maximum and minimum evacuation time of $t_{1}, t_{2}$ and $t_{3}$ in two evacuation scenarios of the 90 combinations of $d_{1}$ and $d_{2}$.

Another noticeable phenomenon, which can be seen in Figure 7, is that the difference between the maximum value and the minimum value of $t_{1}$ and $t_{2}$ was about $30 \mathrm{~s}$ in unidirectional evacuation, while it was about $40 \mathrm{~s}$ in bidirectional evacuation. This means that the passengers needed to spend more time in the evacuation walkway risk zone in bidirectional evacuation. The reason is that, in unidirectional evacuation, the passengers did not need to choose exits in the evacuation walkway risk zone. However, in bidirectional evacuation, the passengers were allowed to select any exit during evacuation. Therefore, they could continuously search for the shortest way to evacuate, and this searching behaviour increased the time of evacuation.

The evacuation time for carriages, i.e., for all the passengers to get away from each carriage was also a noticeable point. The evacuation time for the passengers to alight from each carriage in all of the simulations $(5 \times 90=450)$, in both unidirectional and bidirectional evacuations, is shown in the scatter diagram in Figure 8.
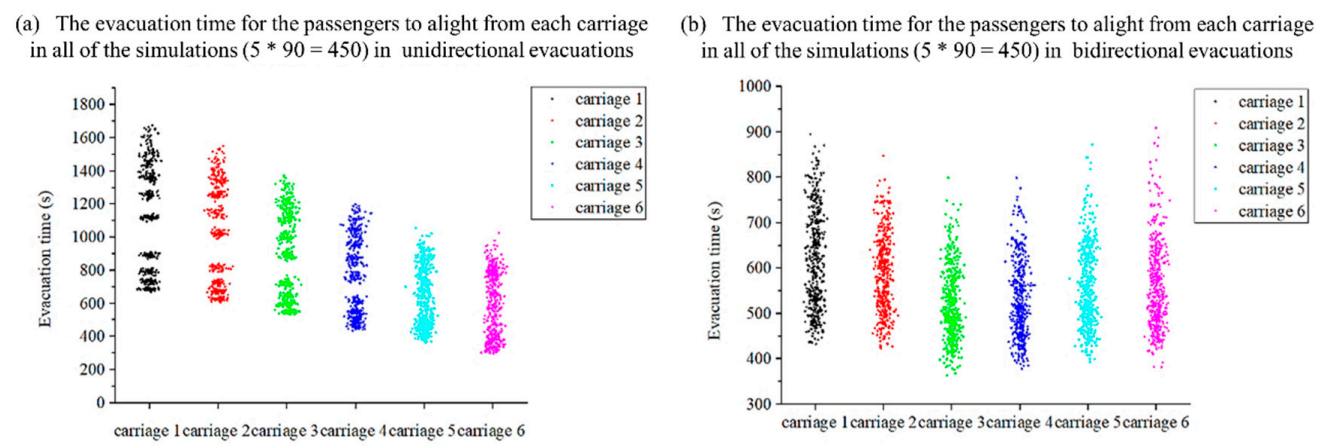

Figure 8. The evacuation time for each carriage for 90 combinations of $d_{1}$ and $d_{2}$. (a) Unidirectional evacuation and (b) bidirectional evacuation. 
In Figure 8a, in unidirectional evacuation, the evacuation time showed a decreasing trend from carriage 1 to carriage 6 . Carriage 1 , which was the nearest to the left station exit, took the longest to evacuate, while carriage 6, which was the farthest away, took the shortest. In Figure 8b, in bidirectional evacuation, the time was dependent on the location of the carriage, i.e., evacuation in carriage 1 and carriage 6 (nearest to the station exits) took longer, compared to carriage 3 and 4 , which lay in the middle of the train. Generally, the closer the train carriage to the safety exit, the longer it took to completely evacuate the passengers. This phenomenon was due to the passenger setting in the simulation, in which the passengers prefered to move and gather closer to the safety exits during the evacuation.

\subsection{Evacuation Time vs. Walkway Width and Entrance Width}

\subsubsection{In Unidirectional Evacuation}

Figure 9 illustrates the evacuation times, $t_{1}, t_{2}$ and $t_{3}$, with different evacuation entrance width, $d_{1}$, and walkway width, $d_{2}$, combinations in unidirectional evacuation.

(a)

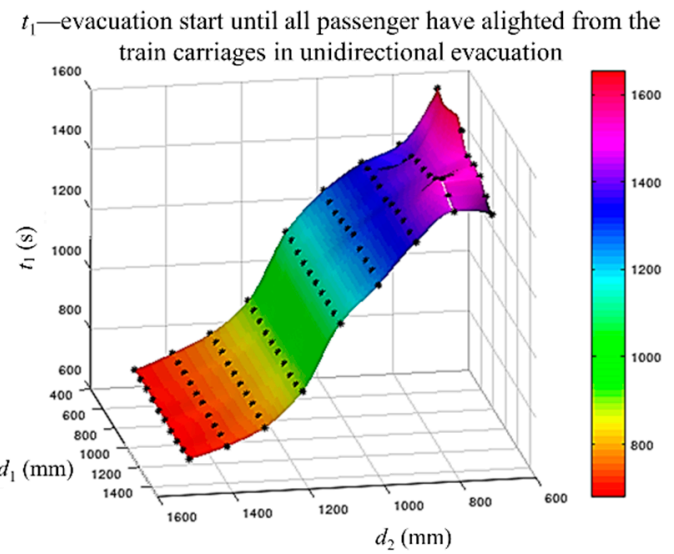

(b)

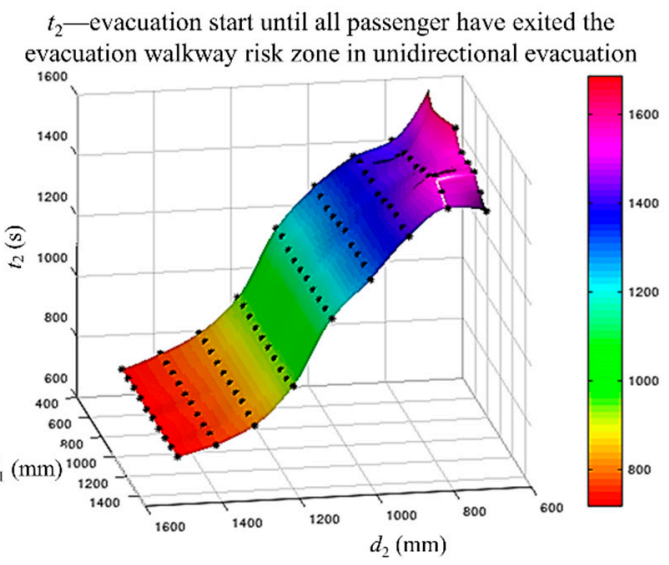

(c) $t_{3}$-total evacuation time, start until all passenger have passed through safety exits in unidirectional evacuation

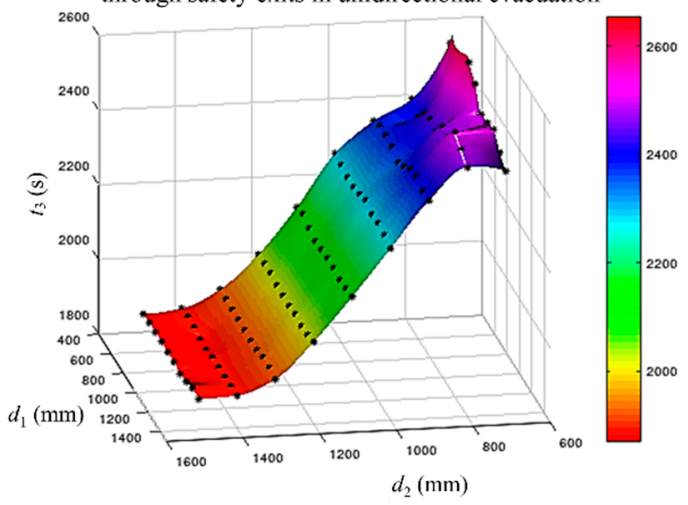

Figure 9. The evacuation time, $t_{1}, t_{2}$ and $t_{3}$, for unidirectional evacuation. (a) $t_{1}$-evacuation time, until all passengers had alighted from the train carriages; (b) $t_{2}$-evacuation time, until all passengers had exited the evacuation walkway risk zone; (c) $t_{3}$-total evacuation time start, until all passenger passed through the safety exits. The interpolation function, "interp1", with the method, "cubic", in MATLAB, was used to create the visual effect of the data changing trend. The black spot represents the average value of the evacuation time for each combination.

From Figure 9, it can be seen that the increase in the entrance width, $d_{1}$, resulted in a fluctuation in the evacuation time of different degrees, when the walkway width was set at different values. When the evacuation walkway width, $d_{2}$, was set to $0.7 \mathrm{~m}$ and $0.8 \mathrm{~m}, t_{1}, t_{2}$ and $t_{3}$ increased first and then 
decreased with the increase of the entrance width, $d_{1}$. When $d_{2}$ was within the range of $0.9-1.5 \mathrm{~m}, t_{1}, t_{2}$ and $t_{3}$ did not change much, when the entrance width, $d_{1}$, increased.

In addition, increasing the evacuation walkway width, $d_{2}$, significantly reduced the evacuation time, $t_{1}, t_{2}$ and $t_{3}$. The most significant downward trend occurred when the evacuation walkway width was increased from $0.9 \mathrm{~m}$ to $1.3 \mathrm{~m}$, whereas only a gentle descent was observed at $0.7-0.8 \mathrm{~m}$ and 1.4-1.5 m, respectively. This is because of the availability of the space on the evacuation walkway. When the evacuation walkway width, $d_{2}$, was within the range of $0.7-0.8 \mathrm{~m}$, only one row could be formed. However, when $d_{2}$ was within the range of $0.9-1.3 \mathrm{~m}$, the passengers were able to walk in two rows, which effectively reduced the evacuation time. In the case of $d_{2}$ being within the range of 1.4-1.5 m, the passengers exhibited a competitive behaviour, i.e., trying to get ahead of each other. Thus, no significant reducing effect on evacuation time was observed when $d_{2}$ was with the range of $1.4-1.5 \mathrm{~m}$.

\subsubsection{In Bidirectional Evacuation}

Figure 10 illustrates the evacuation time, $t_{1}, t_{2}$ and $t_{3}$, with different evacuation entrance width, $d_{1}$, and walkway width, $d_{2}$, combinations in bidirectional evacuation.
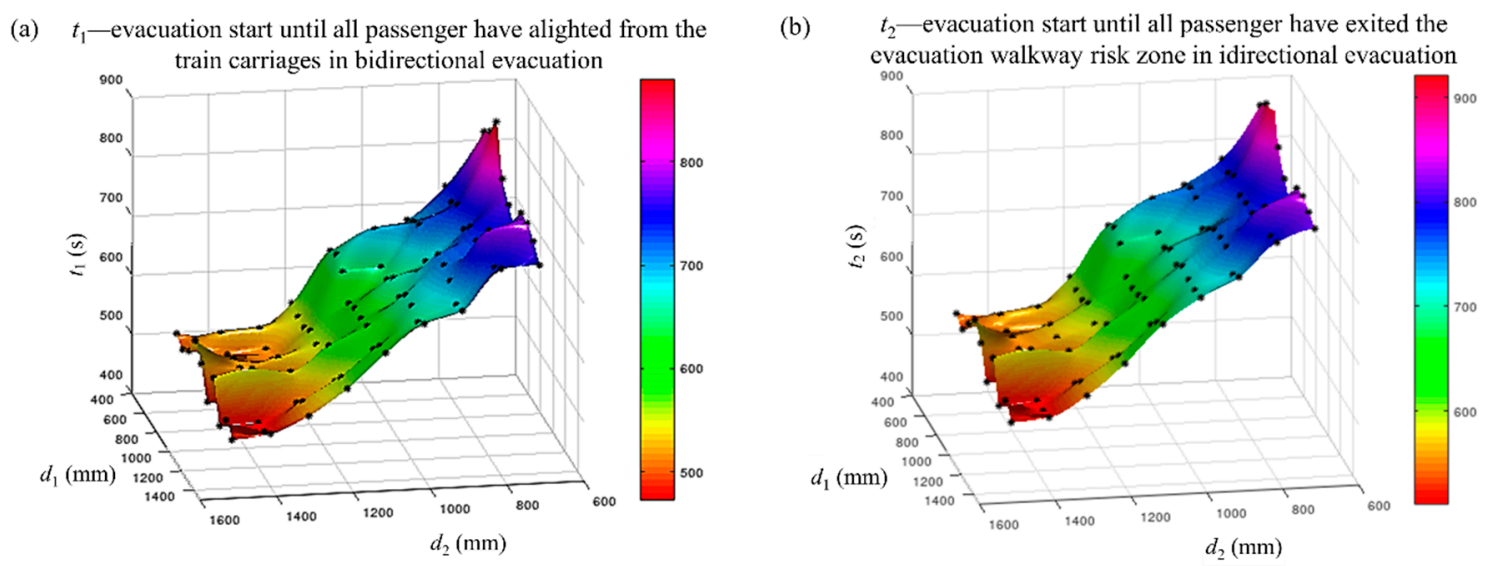

(c) $t_{3}$-total evacuation time, start until all passenger have passed

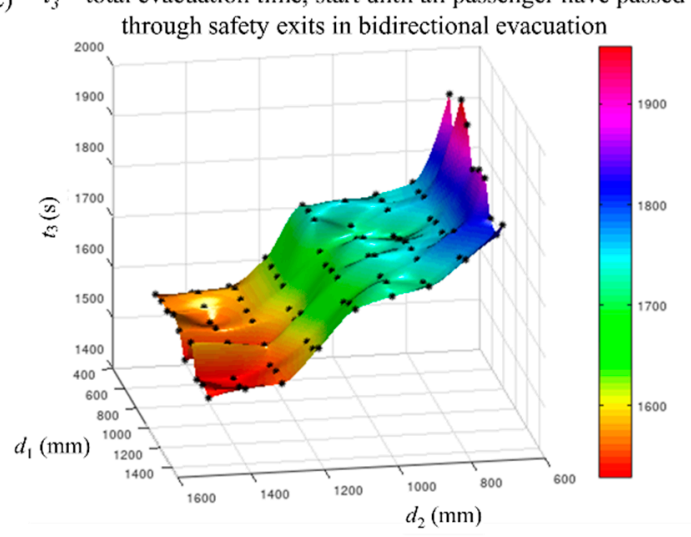

Figure 10. The evacuation time, $t_{1}, t_{2}$ and $t_{3}$, for bidirectional evacuation. (a) $t_{1}$-evacuation time, until all passenger had alighted from the train carriages; (b) $t_{2}$ - evacuation time, until all passenger had exited the evacuation walkway risk zone; (c) $t_{3}$-total evacuation time, until all passenger had passed through the safety exits. The interpolation function, "interp1", with method, "cubic", in MATLAB, was used to create the visual effect of the data changing trend. The black spot represents the average value of the evacuation time for each individual combination.

From Figure 10, it can be seen that, in general, the evacuation time, $t_{1}, t_{2}$ and $t_{3}$, fluctuated more, compared to those in unidirectional evacuation, as shown in Figure 9. The fluctuations caused by the 
increase of $d_{1}$ is more noticeable, when the evacuation walkway width, $d_{2}$, is equal to $0.7 \mathrm{~m}, 0.8 \mathrm{~m}$, $1.4 \mathrm{~m}$ or $1.5 \mathrm{~m}$, and the opposite is the case when $d_{2}$ is within the range of $0.9-1.3 \mathrm{~m}$.

One possible reason for this might be that when $d_{2}$ is relatively narrow, the increase in $d_{1}$ allows more passengers to walk into the risk zone of the evacuation walkway, but the available space in this area is limited. This inconsistency caused a chaotic situation in the simulation, where the passengers gathered around the train door but were not able to evacuate effectively. On the other hand, when $d_{2}$ is relatively wide, the increase in $d_{1}$ resulted in more passengers trying to get away from the train and consequently led to a competitive behaviour in the risk zone of the evacuation walkway. In addition, increasing the evacuation walkway width, $d_{2}$, also significantly reduced the evacuation time, $t_{1}, t_{2}$ and $t_{3}$, which was a similar trend to the unidirectional evacuation.

\section{Discussion}

\subsection{The Combined Effect of the Entrance Width and Walkway Width on the Evacuation Time}

According to the simulation results of $t_{1}, t_{2}$ and $t_{3}$ shown in Figures 9 and 10, it can be observed that there is a combined effect of the entrance width, $d_{1}$, and the walkway width, $d_{2}$, on the evacuation time, both in unidirectional and bidirectional evacuation.

To quantify the combined effect, the average evacuation time of $t_{1}, t_{2}$ and $t_{3}$ with the same $d_{2}$ in both evacuation scenarios was calculated (see Figure 11). It can be observed that when $d_{2}$ is increased from $0.7 \mathrm{~m}$ to $1.5 \mathrm{~m}$, the average evacuation time of $t_{1}, t_{2}$ and $t_{3}$ was reduced by $55.9 \%, 54.5 \%$ and $26.2 \%$, respectively, in unidirectional evacuation, and $36.3 \%, 35.2 \%$ and $17.0 \%$, respectively, in bidirectional evacuation. An increase in the walkway width, $d_{2}$, resulted in a more significant reduction of the evacuation time in unidirectional evacuation than in bidirectional evacuation.

(a) Average evacuation time of $t_{1}, t_{2}$ and $t_{3}$ for combinations with same $d_{2}$ in unidirectional evacuation

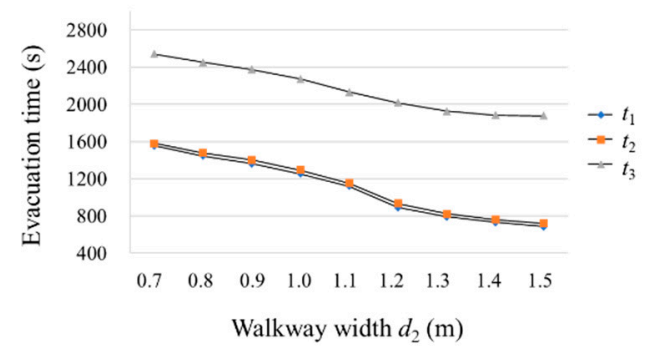

(b) Average evacuation time of $t_{1}, t_{2}$ and $t_{3}$ for combinations with same $d_{2}$ in bidirectional evacuation

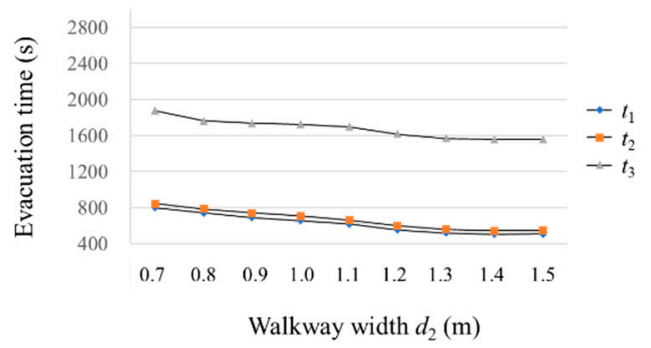

Figure 11. Average evacuation time of $t_{1}, t_{2}$ and $t_{3}$ for the combinations with the same $d_{2}$ in (a) unidirectional evacuation and $(\mathbf{b})$ bidirectional evacuation.

As shown in Figures 9 and 10, it also can be observed that the evacuation time fluctuations were obvious in both the unidirectional and bidirectional evacuation scenarios, when the walkway width was 0.7 and $0.8 \mathrm{~m}$. However, in bidirectional evacuation, a more noticeable fluctuation can be observed when the walkway width was with in the range of 1.4-1.5 m. In general, the increase of $d_{1}$ resuted in the evacuation time varying in different degrees when $d_{2}$ was set to different values, as well as in different evacuation scenarios.

Within the range of the two parameters discussed in this article, the combined effect of the entrance width and walkway width on evacuation time may be that increasing the walkway width significantly reduces the evacuation time, and the reduction is more noteworthy for unidirectional evacuation than for bidirectional evacuation. Besides, the increase in the entrance width, $d_{1}$, resulted in a more obvious evacuation time fluctuation in bidirectional evacuation compared to that in unidirectional evacuation. 


\subsection{Simulation Results Compared to Empirical Formula Results}

The simulated evacuation time were also compared to the conventional empirical formula of the Code of Safety Evacuation for the Metro of China [42] (see Table 4). In the empirical formula, the total evacuation time, $T_{\text {total }}$, is defined as:

$$
T_{\text {total }}=T_{\text {pre-a }}+T_{\text {tr }}+T_{\text {pass }}
$$

where

$T_{\text {pre-a }}$ - passengers' pre-action time.

$T_{t r}$ - passengers evacuated from the train.

$T_{\text {pass }}$ - passengers evacuated on the passageway.

Note that in the conventional empirical formula, the entrance width of the evacuation walkway is not a consideration. Therefore, $T_{t r}$ is only affected by the walkway width, $d_{2}$. Besides, $T_{\text {pass }}$ is related to the passenger volume and walking distance on the passageway from the point of evacuation to safety (the station). To make the simulation results comparable to the empirical ones, the average evacuation time, $t_{3}$, of the simulations with the same walkway width, $d_{2}$, was used.

Table 4. Comparison of the empirical formula and simulation.

\begin{tabular}{|c|c|c|c|c|c|c|c|c|}
\hline \multirow{3}{*}{$\begin{array}{l}\text { Evacuation } \\
\text { Walkway } \\
\text { Width } d_{2} \\
\text { (m) }\end{array}$} & \multirow{3}{*}{$\begin{array}{l}T_{\text {pre-a }} \\
\text { (min) }\end{array}$} & \multirow{3}{*}{$\begin{array}{c}T_{\mathrm{tr}} \\
(\mathrm{min})\end{array}$} & \multicolumn{4}{|c|}{ Empirical Formula } & \multirow{2}{*}{\multicolumn{2}{|c|}{$\begin{array}{c}\text { Simulation } \\
\text { Average of Total Evacuation } \\
\text { Time, } t_{3} \\
\text { (min) }\end{array}$}} \\
\hline & & & \multicolumn{2}{|c|}{$\begin{array}{l}T_{\text {pass }} \\
\text { (min) }\end{array}$} & \multicolumn{2}{|c|}{$T_{\text {total }}=\underset{(\text { min) }}{T_{\text {pre-a }}+T_{\text {tr }}+T_{\text {pass }}}$} & & \\
\hline & & & Unidirectional & Bidirectional & Unidirectional & Bidirectional & Unidirectional & Bidirectional \\
\hline 0.7 & 2 & 24.6 & 19.6 & 16.2 & 41.3 & 37.9 & 42.4 & 31.3 \\
\hline 0.8 & 2 & 21.5 & 19.6 & 16.2 & 38.8 & 35.4 & 40.9 & 29.4 \\
\hline 1.1 & 2 & 15.6 & 19.6 & 16.2 & 34.1 & 30.7 & 35.6 & 28.3 \\
\hline 1.2 & 2 & 14.3 & 19.6 & 16.2 & 33.1 & 29.7 & 33.6 & 26.9 \\
\hline 1.3 & 2 & 13.2 & 19.6 & 16.2 & 32.2 & 28.8 & 32.1 & 26.1 \\
\hline 1.4 & 2 & 12.3 & 19.6 & 16.2 & 31.5 & 28.1 & 31.4 & 26.0 \\
\hline 1.5 & 2 & 11.5 & 19.6 & 16.2 & 30.8 & 27.4 & 31.3 & 26.0 \\
\hline
\end{tabular}

A decrease in the evacuation time was observed in both the empirical formula and the simulations with the increase of $d_{2}$. For unidirectional evacuation, the simulation results are similar to the empirical results, and the difference was within the range of $0.1-2.7 \mathrm{~min}$. This is probably because the passengers had only one direction to choose during the evacuation, so they evacuated in a more orderly manner. For bidirectional evacuation, the difference between the simulation results and the empirical results is bigger than that in unidirectional evacuation. This is probably because passenger behavior in bidirectional evacuation, e.g., the process of choosing exits, competitive behavior, etc., was more complex and noticeable. This behavior can be represented in detail with the steering mode in Pathfinder, but it may not be described in detail in the empirical formula. Therefore, the difference between the evacuation time according to the empirical formula and the simulation is slightly larger in the bidirectional evacuation.

Besides, in both unidirectional and bidirectional evacuation, although larger walkway widths were set in the simulations, the evacuation time did not show a great improvement, i.e., a walkway width of 1.3-1.5 $\mathrm{m}$ did not cause a drastic decrease in the evacuation time.

Generally, the empirical formula provides more conservative results. However, it still might be concluded that the empirical formula and the Pathfinder are in better agreement regarding the prediction of the evacuation time in unidirectional evacuation. However, in bidirectional evacuation, or a more complicated evacuation, a numerical simulation with the capability of including passenger behavior might provide more detailed insight.

In addition, the new evacuation time measurement method, $t_{1}, t_{2}$ and $t_{3}$, proposed in this study could be seen as a novel trial for evacuation time study in relation to elevated rail transit systems. 
One advantage of this method is that the evacuation time and the evacuation process on the elevated lines can be analyzed more accurately and flexibly and be understood more intuitively. For example, $t_{1}$ (evacuation time, until all passengers had exited the train carriage zone) is helpful to find the most crowded and the most evacuation time costly carriages. In this paper, it is revealed that the most congested carriages in interval evacuation are those closest to the safety exits in the station, i.e., both ends of the train.

The other advantage of this measurement is that $t_{2}$ (evacuation time, until all passengers had exited the evacuation walkway risk zone) is a more suitable measurement reference, compared to $T_{\text {total }}$, in studying evacuation walkway design. This is because, when a train is caught in an accident on an elevated railway line, the dangerous area is more likely to be around the train. Thus, shortening the evacuation time, $t_{2}$, for passengers to leave the evacuation walkway risk zone is more important than the whole evacuation time.

\subsection{Suggestions for Evacuation Walkway Parameter Design}

As discussed above, combinations of $d_{1}$ and $d_{2}$ corresponding to the shortest $t_{2}$ in both directions were listed in Table 5. As shown in the results, for both evacuation directions, $t_{2}$ decreased dramatically with the increase of $d_{2}$, until the width of the walkway was $1.3 \mathrm{~m}$, but an increase of $d_{2}$ greater than $1.3 \mathrm{~m}$ did not cause a significant reduction in $t_{2}$.

Therefore, in this study, it might be safe to assume that a $d_{2}$ of $1.3 \mathrm{~m}$ is an ideal width for new elevated transit line evacuation walkways, and the entrance width, $d_{1}$, is suggested to be $1.4 \mathrm{~m}$, as this combination might potentially help to reduce the evacuation time, $t_{2}$, from $1295 \mathrm{~s}$ to $814 \mathrm{~s}$, reduced by $37.2 \%$, compared to the current design practice $\left(d_{1}=0.5 \mathrm{~m}\right.$, and $\left.d_{2}=1.0 \mathrm{~m}\right)$ in the unlikely event of unidirectional evacuation. For a restricted construction condition, where the evacuation walkway width, $d_{2}$, is $0.7 \mathrm{~m}$, the evacuation time, $t_{2}$, may potentially be reduced from $1606 \mathrm{~s}$ to $1485 \mathrm{~s}$ by changing the entrance width of $0.5 \mathrm{~m}$ to $1.4 \mathrm{~m}$. Meanwhile, for the evacuation walkway width, $d_{2}=1.0 \mathrm{~m}$, which is currently the normal practice, the evacuation time, $t_{2}$, may potentilly be reduced from $1295 \mathrm{~s}$ to $1278 \mathrm{~s}$ by changing the entrance width of $0.5 \mathrm{~m}$ to $1.4 \mathrm{~m}$. Generally, a broader entrance width that is $1.4 \mathrm{~m}$ (the train door width in this study) or as wide as possible is suggested.

Table 5. Combinations of $d_{1}$ and $d_{2}$ corresponding to the shortest $t_{2}$.

\begin{tabular}{ccccc}
\hline \multirow{2}{*}{$\begin{array}{c}\text { Evacuation Walkway } \\
\text { Width, } \boldsymbol{d}_{\mathbf{2}} \mathbf{( \mathbf { m } )}\end{array}$} & \multicolumn{2}{c}{ Unidirectional Evacuation } & \multicolumn{2}{c}{ Bidirectional Evacuation } \\
\cline { 2 - 5 } & $\begin{array}{c}\text { Entrance Width, } \\
\boldsymbol{d}_{\mathbf{1}}(\mathbf{m})\end{array}$ & $\begin{array}{c}\text { The Minimum } \\
\text { Value of } \boldsymbol{t}_{\mathbf{2}} \mathbf{( s )}\end{array}$ & $\begin{array}{c}\text { Entrance Width, } \\
\boldsymbol{d}_{\mathbf{1}}(\mathbf{m})\end{array}$ & $\begin{array}{c}\text { The Minimum } \\
\text { Value of } \boldsymbol{t}_{\mathbf{2}}(\mathbf{s})\end{array}$ \\
\hline 0.7 & 1.4 & 1485 & 1.0 & 791 \\
0.8 & 0.6 & 1411 & 0.8 & 772 \\
0.9 & 0.5 & 1386 & 0.8 & 720 \\
1.0 & 1.4 & 1278 & 0.8 & 692 \\
1.1 & 0.8 & 1151 & 1.2 & 633 \\
1.2 & 1.2 & 927 & 1.0 & 577 \\
1.3 & 1.4 & 814 & 1 & 531 \\
1.4 & 1.4 & 756 & 1.2 & 516 \\
1.5 & 0.9 & 717 & 1.2 & 511 \\
\hline
\end{tabular}

The limitations of this study are as follows:

- Only one simulation setting, namely, evacuation in the middle of an interval section on an elevated transit line was considered. This setting considered the most likely worst-case scenario during an emergency on an elevated transit line, i.e., with the longest walking distance on both sides to safety exits. In a highly unlikely event, a train might stop close to the station, but only one-way escape is available. This study has also partly covered unidirectional evacuation up to point $t_{2}$ but will have a different $t_{3}$. 
- The total number of evacuation passengers was not set as a variable, but only a maximum number of 1032 is used. This is assumed to be the worst-case evacuation scenario, as fewer people would result in a less chaotic situation. Six carriage marshalling, with a 1032 passenger capacity, was considered in this study, because it is the current maximum passenger capacity and maximum carriage marshalling for a Maglev train operation. The number of carriages and passengers can be set as variable as longer trains might be anticipated in the future.

\section{Conclusions}

This paper contributed to the improvement of passenger evacuation conditions on elevated rail transit lines. Based on literature research and an evacuation scenario survey, a new evacuation time measurement for interval evacuation on elevated rail transit was first introduced. Then, an interval evacuation model on elevated rail transit lines was built using a multi-agent simulator, Pathfinder, with qualitative and quantitative data that were surveyed and collected earlier. After that, the model was used to study the evacuation time for different combinations of evacuation walkway design parameters, namely, the walkway entrance width and walkway width in both unidirectional and bidirectional evacuation. The following conclusions were drawn:

There is a combined effect of the evacuation walkway width and entrance width on the evacuation time in both unidirectional and bidirectional evacuation. Based on the conditions set in the model, it is observed that an increase in the walkway width from $0.7 \mathrm{~m}$ to $1.5 \mathrm{~m}$ may potentially reduce the evacuation time, $t_{2}$, by $54.5 \%$, in unidirectional evacuation, and $35.2 \%$ in bidirectional evacuation. The increase in the walkway entrance width did not cause a great improvement in reducing the evacuation time, but the incease of the entrance width can result in evacuation time fluctuation. The evacuation time fluctuation is more obvious in bidirectional evacuation, compared to unidirectional evacuation.

A reasonable match between the walkway entrance width and walkway width can significantly reduce evacuation time. Therefore, the walkway entrance width and walkway width should be considered together to achieve a shorter evacuation time in evacuation walkway design. Our suggestion for a new evucation walkway design is $1.3 \mathrm{~m}$ and $1.4 \mathrm{~m}$ for the walkway width and entrance width, respectively. This may potentially reduce the passenger evacuation time from the risk zone by $37.2 \%$, compared to the current normal design practice, where the walkway width is $1.0 \mathrm{~m}$, and the entrance width is $0.5 \mathrm{~m}$. In the case of limited space for evacuation walkway construction, $0.7 \mathrm{~m}$ and $1.4 \mathrm{~m}$ for the walkway width and entrance width, respectively, should be adopted. For existing evacuation walkways, which have a typical width of $1 \mathrm{~m}$, enlargement of the entrance to $1.4 \mathrm{~m}$ is recommended.

Author Contributions: Conceptualization, Z.P. and Q.W.; methodology, Z.P., Q.W. and O.T.; software, Z.P. and A.L.; validation, Z.P.; formal analysis, Z.P., Q.W. and A.L.; investigation, Z.P. and Q.W.; data curation, Z.P. and Q.W.; writing—original draft preparation, Z.P., Q.W., O.T. and A.L.;writing—review and editing, Z.P., O.T. and A.L.; visualization, Z.P. and A.L.; supervision, Z.P., Q.W. and O.T.; project administration, Z.P., Q.W. and O.T.; funding acquisition, Q.W. and O.T. All authors reviewed the results and approved the final version of the manuscript.

Funding: This research was funded by the "BEIJING NATURAL SCIENCE FOUNDATION, grant number 8172040", "A SCHOLARSHIP UNDER THE STATE SCHOLARSHIP FUND OF P.R CHINA" and the "NORWEGIAN UNIVERSITY OF SCIENCE AND TECHNOLOGY, grant number 649105".

Acknowledgments: The authors are grateful to the Beijing Natural Science Foundation (Grantno.8172040), the China Scholarship Council and the Norwegian University of Science and Technology for their financial support. The authors are also grateful to Wenjun Lu and Diego Barbieri for providing good advice for the improvement of this paper.

Conflicts of Interest: The authors declare no conflict of interest. The funders had no role in the design of the study; in the collection, analyses, or interpretation of data; in the writing of the manuscript, or in the decision to publish the results. 


\section{References}

1. Xue, H.; Yang, P.; Zhang, H.; Jing, E. Study on the Control Strategy of Urban Rail Transit Passenger Flow under the Condition of Large Passenger Flow. IOP Conf. Ser. Earth Environ. Sci. 2019, 234, 012001. [CrossRef]

2. Burnett, J. Fire Safety Concerns for Rail Rapid Transit Systems. Fire Saf. J. 1984, 8, 3-7. [CrossRef]

3. Kyriakidis, M.; Hirsch, R.; Majumdar, A. Metro Railway Safety: An Analysis of Accident Precursors. Saf. Sci. 2012, 50, 1535-1548. [CrossRef]

4. Gershon, R.R.M.; Qureshi, K.A.; Barrera, M.A.; Erwin, M.J.; Goldsmith, F. Health and Safety Hazards Associated with Subways: A Review. J. Urban Health 2005, 82, 10-20. [CrossRef]

5. Ouyang, M.; Hong, L.; Yu, M.-H.; Fei, Q. STAMP-based Analysis on the Railway Accident and Accident Spreading: Taking the China-Jiaoji Railway Accident for Example. Saf. Sci. 2010, 48, 544-555. [CrossRef]

6. Akabal, F.M.; Masirin, M.I.H.M.; Akasah, Z.A.; Rohani, M.M. Review on Selection and Suitability of Rail Transit Station Design Pertaining to public safety. In Proceedings of the IOP Conference Series: Materials Science and Engineering, Melaka, Malasia, 6-7 May 2017; Volume 226, p. 012033.

7. Vuilleumier, F.; Weatherill, A.; Crausaz, B. Safety aspects of railway and road tunnel: Example of the Lötschberg railway tunnel and Mont-Blanc road tunnel-ScienceDirect. Tunn. Undergr. Space Technol. 2002, 17, 153-158. [CrossRef]

8. Cheng, H.; Yang, X. Emergency Evacuation Capacity of Subway Stations. Procedia Soc. Behav. Sci. 2012, 43, 339-348. [CrossRef]

9. Hunter-Zaworski, K. Analysis of Passenger Incident Data from Five Rail Transit Systems. Safety $2017,3,21$. [CrossRef]

10. Lombardi, M.; Cuarascio, M.; Rossi, G. The Management of Uncertainty: Model for Human Error Probability in Railway System. Am. J. Appl. Sci. 2014, 11, 381-390. [CrossRef]

11. Seike, M.; Kawabata, N.; Hasegawa, M. Experiments of Evacuation Speed in Smoke-filled Tunnel. Tunn. Undergr. Space Technol. 2016, 53, 61-67. [CrossRef]

12. Benn, J. Railway Bridge Failure during Flooding in the UK and Ireland. Proc. Inst. Civ. Eng. Forensic Eng. 2013, 166, 163-170. [CrossRef]

13. Kucera, P.; Bradáčová, I. Modelling the Evacuation of People from a Train on Fire in a Railway Tunnel. In Recent Advances in Engineering. 3rd European Conference of Chemical and Civil Engineering; Angrey, D., Catarina, L.C., Eds.; WSEAS Press: Paris, France, 2012; pp. 196-201.

14. Chen, S.-K.; Li, S.-Y.; Li, X.; Hong, J.; Lai, J.-X.; Cai, P. Modeling Evacuation Time for Passengers from Metro Platforms. J. Transp. Syst. Eng. Inf. Technol. 2008, 8, 101-107.

15. Li, Y.; Liu, S. Passenger Evacuation in Subway Transit Tunnels Installed with Side Evacuation Platforms. Urban Rapid Rail Transit 2007, 20, 13-16.

16. Zhai, W.; Zhao, C. Dynamics of Maglev Vehicle/Guidway Systems(I)-Magnet/Rail Interaction and System Stability. Chin. J. Mech. Eng. 2005, 41, 1-10. [CrossRef]

17. Fitting Out The Railway. Available online: http://www.crossrail.co.uk/construction/railway-systems/ (accessed on 24 September 2019).

18. Habicht, A.T.; Braaksma, J.P. Effective Width of Pedestrian Corridors. J. Transp. Eng. 1984, 110, 80-93. [CrossRef]

19. Lundström, F.V.; Ahlfont, J.; Nilsson, D. The Effect of Raised Walkway Design on Evacuation Behaviour in Rail Tunnels. Fire Saf. Sci. 2014, 11, 1091-1102. [CrossRef]

20. European Commision. Commision Decision of 20 December 2007. Concerning the Technical Specification of Interoperability Relating to 'Safety in Railway Tunnels' in the Trans-European Conventional and High-Speed Rail System. 2008. Available online: https://eur-lex.europa.eu/LexUriServ/LexUriServ.do?uri=CONSLEG: 2008D0163:20130124:EN:PDF (accessed on 31 October 2019).

21. Standardization Administration of the People's Republic of China. Code for Design of Metro; Standardization Administration of the People's Republic of China: Beijing, China, 2013; pp. 26-27.

22. Minishty of Housing and Urban-Rural Developement of the People's Republic of China. Code for Design of Medium and Low Speed Maglev Transit; Minishty of Housing and Urban-Rural Developement of the People's Republic of China: Beijing, China, 2017.

23. Helbing, D.; Farkas, I.J.; Molnar, P.; Vicsek, T. Simulation of pedestrian crowds in normal and evacuation situations. Pedestr. Evacuation Dyn. 2002, 21, 21-58. 
24. Fridolf, K.; Nilsson, D.; Frantzich, H. The flow rate of people during train evacuation in rail tunnels: Effects of different train exit configurations-ScienceDirect. Saf. Sci. 2014, 62, 515-529. [CrossRef]

25. Cuesta, A.; Abreu, O.; Balboa, A.; Alvear, D. An experimental data-set on merging flows in rail tunnel evacuation. Tunn. Undergr. Space Technol. 2017, 70, 155-165. [CrossRef]

26. Railway Bureau; Ministry of Land, Infrastructure, Transport and Tourism. Technical Regulatory Standards on Japanese Railways; Railway Bureau; Ministry of Land, Infrastructure, Transport and Tourism: Tokyo, Japan, 2012; p. 196.

27. Reynolds, C.W. Steering behaviors for autonomous characters. In Proceedings of the Game Developers Conference, San Jose, CA, USA, 15-19 March 1999; Volume 1999, pp. 763-782.

28. Heni, A.; Jan, M.; Oliver, O. Fast, Neat, and Under Control: Arbitrating Between Steering Behaviors. AI Game Program. Wisdom 2006, 3, 221-232.

29. Thornton, C.; O'Konski, R.; Hardeman, B.; Swenson, D. Pathfinder: An Agent-Based Egress Simulator. In Pedestrian and Evacuation Dynamics; Peacock, R.D., Kuligowski, E.D., Averill, J.D., Eds.; 2011; pp. 889-892.

30. Thornton, C.; O'Konski, R.; Klein, B.; Hardeman, B.; Swenson, D. New Wayfinding Techniques in Pathfinder and Supporting Research. In Pedestrian and Evacuation Dynamics 2012; Weidmann, U., Kirsch, U., Schreckenberg, M., Eds.; Springer International Publishing: Berlin/Heidelberg, Germany, 2014; pp. 1315-1322.

31. Thunderhead Engineering. Technical Reference of Pathfinder. Available online: https://www.thunderheadeng. com/pathfinder/resources/ (accessed on 28 September 2019).

32. Thunderhead Engineering. Pathfinder Vertification and Validation. Available online: https://www. thunderheadeng.com/pathfinder-verification-validation-archive/ (accessed on 28 September 2019).

33. Ronchi, E.; Colonna, P.; Capote, J.; Alvear, D.; Berloco, N.; Cuesta, A. The Evaluation of Different Evacuation Models for Assessing Road Tunnel Safety Analysis. Tunn. Undergr. Space Technol. 2012, 30, 74-84. [CrossRef]

34. Wang, H.; Chen, Q.; Yan, J.; Yuan, Z.; Liang, D. Emergency Guidance Evacuation in Fire Scene Based on Pathfinder. In Proceedings of the 2014 7th International Conference on Intelligent Computation Technology and Automation, Changsha, China, 25-26 October 2014; pp. 226-230.

35. White, N.; Dowling, V.P.; Barnett, J.R. Full-scale Fire Experiment On A Typical Passenger Train. Fire Saf. Sci. 2005, 8, 1157-1168. [CrossRef]

36. Chiam, B.H. Numerical Simulation of a Metro Train Fire. Master's Thesis, University of Canterbury: Christchurch, Canterbury, New Zealand, 2005.

37. Linteris, G.T.; Rafferty, I.P. Flame size, heat release, and smoke points in materials flammability. Fire Saf. J. 2008, 43, 442-450. [CrossRef]

38. Minishty of Housing and Urban-Rural Developement of the People's Republic of China. Code for Fire Protection Design of Buildings; Minishty of Housing and Urban-Rural Developement of the People's Republic of China: Beijing, China, 2018.

39. Wenting, L. Research on Passengers Capacity of Emergency Evacuation in Subway. Master's Thesis, Tongji University, Shanghai, China, 2008.

40. Research on Emergency Evacuation Behaviour of Passengers in Subway Station Fire. Master's Thesis, Hunan University of Science and Technology, Hunan, China, 2012.

41. Hurley, M.J.; Gottuk, D.T.; Hall, J.R., Jr.; Harada, K.; Kuligowski, E.D.; Puchovsky, M.; Watts, J.M., Jr.; WIECZOREK, C.J. SFPE Handbook of Fire Protection Engineering; Springer: Berlin/Heidelberg, Germany, 2015; ISBN 978-1-4939-2565-0.

42. Standardization Administration of the People's Republic of China. Code for Safety Evacuation of Metro; Standardization Administration of the People's Republic of China: Beijing, China, 2017; pp. 8-10.

(C) 2019 by the authors. Licensee MDPI, Basel, Switzerland. This article is an open access article distributed under the terms and conditions of the Creative Commons Attribution (CC BY) license (http://creativecommons.org/licenses/by/4.0/). 